\title{
Considerações Sobre os Marcadoves Bioquímicos do Metabolismo Ósseo e sua Utilidade Prática
}

\section{RESUMO}

O uso de marcadores bioquímicos do metabolismo ósseo na prática clínica tem se expandido de maneira considerável. Isto se deve ao surgimento de novos métodos e de um melhor conhecimento sobre a fisiopatologia das doenças ósteo-metabólicas, em especial a osteoporose. Os marcadores podem ser divididos em marcadores de formação, que refletem a atividade dos osteoblastos, e os de reabsorção, que refletem a atividade dos osteoclastos. Dentre os primeiros destacam-se a fosfatase alcalina óssea e a osteocalcina, e dentre os últimos os fragmentos derivados da reabsorção do colágeno, como as piridinolinas e os telopeptídeos carboxi e amino terminais. Além das aplicações já consagradas, como o diagnóstico e acompanhamento de patologias com importantes repercussões ósseas como a doença de Paget, o hiperparatiroidismo primário e outras, novas aplicações têm sido estudadas. Dentre estas, a que mais parece fundamentada é o acompanhamento do efeito de terapêutica específica no tratamento da osteoporose; a curto prazo, 1 a 3 meses, é possivel a verificação da eficácia terapêutica, fato só possivel com densitometria óssea após 1 a 2 anos. Novos métodos, em especial para a medida de marcadores de reabsorção no soro, devem tornar ainda mais abrangente a aplicação destes ensaios. (Arq Bras Endocrinol Metab 1999; 43/6: 415-422)

Unifermos: Marcadores bioquímicos do metabolismo ósseo, marcadores de formação óssea e reabsorção óssea

\begin{abstract}
The use of biochemical markers of bone turnover in clinical practice is an ever increasing field. The development of new methods and a better knowledge of the physiopathology of the bone diseases, mainly osteoporosis, are the main reason for that. The markers can be divided in formation markers, that reflect osteoblastic activity, and resorption markers that reflect osteoclastic activity. Among the first ones the most important are bone specific alkaline phosphatase and osteocalcin, and among the last ones the fragments derived from the metabolism of collagen, like pyridolines and the amino and carboxyl terminal telopeptides. Besides the well proved applications, like the diagnosis and follow-up of diseases with important bone effects, like Paget's disease, primary hyperparathyroidism and others, new applications have recently been studied. Among these the one that seems to be more consistent is the follow-up of patients submitted to treatment for osteoporosis; in a short time curse. 1 to 3 months, is possible to verify the efficacy of a given medical treatment, something you can only verify using bone densitometry after one or two years. New methods, in special for the measurement of resorption markers in serum, may turn the application of these assays even more disseminated. (Arq Bras Endocrinol Metab 1999; 43/6; 415-422)
\end{abstract}

Keywords: Biochemical markers of bone metabolism, markers of bone formation, markers of bone resorption Disciplina de Endocrinologia da
$E P M / U N I F E S P$,
São Paulo, $S P$ 
$\mathbf{O}$ USO DE MÉTODOS LABORATORIAIS QUE PERMITAM a avaliação do metabolismo ósseo de uma maneira confiável, rápida e prática tem sido um objetivo de há muito almejado pelos pesquisadores que atuam nessa área. O tecido ósseo apresenta uma série de características muito peculiares, dentre elas a grande extensão e distribuiçăo, e a presença de cristais radiopacos. Estes últimos propiciam o exame do esqueleto de uma maneira muito simples, através do emprego de técnicas de absorção de raio-X, quer qualitativas (raio-X simples), quer quantitativas (densitometria óssea ou tomografia quantitativa). No entanto, os fenômenos metabólicos, fisiológicos ou patológicos, que podem atingir o tecido ósseo só afetam significativamente sua estrutura radiopaca após um lapso de tempo considerável. Isto toma o emprego destas técnicas limitado para o estudo mais dinâmico, e a curto prazo, do metabolismo ósseo. Daí o interesse sobre metodologias que possam quantificar substâncias que poderiam representar os processos metabólicos em curso no tecido.

\section{O TECIDO ÓSSEO}

Os ossos são um tecido metabolicamente ativo que sofre um processo contínuo de renovação e remodelação. Esta atividade ć conseqüência, em sua maior parte, da atividade de dois tipos celulares principais, característicos do tecido ósseo: os osteoblastos e os osteoclastos. Um terceiro tipo celular, os osteócitos, derivados dos osteoblastos, são metabolicamente menos ativos, e sua função menos conhecida. O processo de remodelação óssea se desenvolve com base em dois processos antagônicos mas acoplados: a formação e a reabsorção ósseas. O acoplamento dos dois processos permite a renovação e remodelação ósseas e é mantido a longo prazo por um complexo sistema de controle que inclui hormônios, fatores físicos e fatores humorais locais. Uma série de condições como idade, doenças ósteo-metabólicas, mobilidade diminuída, ação de algumas drogas, etc., podem alterar este equilíbrio entre formação e reabsorção, levando ao predomínio de um sobre o outro.

Os dois principais tipos de tecido ósseo são o trabecular, uma estrutura de aspecto esponjoso; c o cortical, mais sólido e formado por lamelas ósseas. Além das diferenças estruturais, os dois tipos diferem também quanto a outros aspectos como a distribuição espacial das células, densidade da matriz mineralizada, distribuição dos vasos sangüíneos e área ocupada pela medula óssea. Em ambos, os osteoblastos e osteoclastos movem-se sobre a superficie, sendo que os osteoblastos podem tornar-se embebidos na matriz, dando origem aos osteócitos. Em função de sua maior superfície em relação ao volume, o osso trabecular é metabolicamente mais ativo que o cortical.

\section{OS MARCADORES BIOQUIMMICOS DO METABOLISMO ÓSSEO}

Marcadores bioquímicos do metabolismo ósseo são empregados na prática clínica há muitas décadas, em especial o estudo da fosfatase alcalina total sérica, a calciúria e a hidroxiprolinúria. A falta de especificidade destes marcadores tradicionais levou seu uso a ser restrito ao estudo de patologias ósseas onde as alterações são muito marcadas, como, por exemplo, a doença de Paget. Avanços recentes no isolamento e caracterização das células e dos componentes extracelulares da matriz óssea, resultaram no desenvolvimento de métodos para a medida sérica ou urinária de novos marcadores bioquímicos do metabolismo ósseo. Podemos definir marcadores bioquímicos do metabolismo ósseo como substâncias que retratam a formação ou a reabsorção ósseas. Como a formação é dependente da ação dos osteoblastos, os marcadores de formação, na realidade, medem produtos decorrentes da ação destas células; da mesma maneira, os marcadores de reabsorção medem a ação dos osteoclastos, o principal tipo celular envolvido na reabsorção da matriz óssea. Consequentemente, no caso dos marcadores de formação, são todos eles fruto de síntese osteoblástica, enquanto os de reabsorção são produto da atuação do osteoclasto sobre a matriz óssea.

Normalmente, como o processo de formação é estreitamente ligado ao de reabsorção, um marcador que reflete reabsorção também reflete formação; isto quando o tecido ósseo está em equilíbrio, como durante o intervalo entre a terceira e quinta décadas de vida. Durante o período de vida adulta, a atividade metabólica óssea, e consequentemente os níveis dos marcadores, tendem a ser mais baixos que os observados na infầncia e adolescência (1). Se bem que não plenamente documentado, poderíamos esperar que os marcadores de formação óssea fossem proporcionalmente mais elevados durante a infância e adolescência do que os de reabsorção. Durante a gravidez e lactação, o metabolismo ósseo também é mais acelerado, resultando $\mathrm{em}$ aumento dos níveis dos marcadores de formação e reabsorção (2). Após a menopausa, os marcadores também tendem a se elevar, com os marcadorcs de reabsorção apresentando um incremento maior que os de formação (3). Diferentemente, os níveis de marcadores permanecem estáveis no sexo masculino até a oitava década de vida (4). 
Doenças ósseas alteram o padrão de produção dos marcadores bioquímicos. Doenças que levam a osteopenia tendem a aumentar a relação entre os marcadores de reabsorção e os de formação, como parece ser o caso na osteoporose (3). Por outro lado, em condições patológicas como a osteopetrose, espera-se um incremento maior dos marcadores de formação. Além disto, os marcadores de formação óssea atualmente em uso refletem a atividade osteoblástica em diferentes estágios de diferenciação deste tipo celular. Durante a formação do osso, a produção da matriz colágena precede a mineralização. A fase de produção de matriz colágena coincide com uma maior produção de fosfatase alcalina, enquanto a mineralização coincide com uma maior produção de osteocalcina (5). Em função disto, doenças que alteram a diferenciação osteoblástica tendem a alterar a relação entre os marcadores de formação. Tal fenômeno pode ser observado na doença de Paget, onde o aumento dos níveis de fosfatase alcalina óssea ć proporcionalmente bem maior que os de osteocalcina, sugerindo uma alteração na diferenciação dos osteoblastos (6). Os estados de deficiência de vitamina $\mathrm{D}$ também são caracterizados por uma alteração na diferenciação dos osteoblastos, daí o desproporcional aumento dos níveis de fosfatase alcalina encontrados na osteomalácia (7).

\section{COMENTÁRIOS GERAIS SOBRE OS MARCADORES BIOQUIMIICOS DE METABOLISMO ÓSSEO ATUALMENTE EM USO}

Os principais marcadores bioquímicos do metabolismo ósseo atualmente em uso estão listados na tabela 1 , divididos entre os que refletem formação e os que refletem reabsorção. O número de marcadores já descritos é evidentemente maior; no entanto, nos preocupamos em listar apenas aqueles que apresentam um real interesse prático, com comprovação recente de aplicação clínica. É interessante notar que com as metodologias atualmente disponíveis, os marcadores de formação são todos medidos no soro, enquanto que os de reabsorção em amostras de urina (com exceção dos pouco empregados telopeptídeo carboxiterminal do procolágeno tipo $1, \mathrm{e}$ da fosfatase ácida tartrato resistente). Isto faz com que os marcadores de formação apresentem coleta mais conveniente, além de não necessitarem de medidas adicionais de creatinina para correção. Estas características também têm influênçia na reprodutibilidade dos métodos, desde que quando medimos a creatinina estamos acrescentando o erro intrínseco de mais uma determinação bioquímica. Em consequiiência, os marcadores de reabsorção apresentam uma maior variabilidade de dia para dia, podendo
Tabela 1. Marcadores Bioquímicos do Metabolismo ósseo

Formação
Fosfatase Alcalina Óssea e/ou Total (soro)
Osteocalcina (soro)
Propeptideos do Colágeno Tipo 1 (soro)
Reabsorção
Hidroxiprolina (urina)
Interligados do Colágeno (cross-links) (urina)
Piridinolinas Totais
Piridinolina e /ou Deoxipiridinolina Livre
N-telopeptídeo (NTX)
C-telopeptídeo (CTX)
Fosfatase Ácida Tartrato-Resistente
(soro)

variar em até 30\% num mesmo indivíduo em condições basais (8). Logo, para que variações induzidas pela introdução de terapêtutica específica tenham significado, são necessárias variações acima desses limites.

Outros fatores podem também interferir nos níveis dos marcadores bioquímicos do metabolismo ósseo, independentemente de alterações na remodelação de longa duração. Assim, a remodelação óssea apresenta un ritmo circadiano, com maiores níveis durante a noite (9). Em função disto, a primeira urina da manhã reflete o pico de reabsorção óssea, e apresentará valores seguramente mais altos que uma amostra colhida em outra horário. Quanto aos marcadores séricos de formação, um aspecto importante a considerar na indicação e interpretação dos valores é a significativa diferença de meiavida biológica entre fosfatase alcalina óssea (em torno de 1,6 dias) e ostcocalcina (menos de 1 hora). Logo, fenômenos agudos são melhor representados pelos níveis de osteocalcina, enquanto os níveis de fosfatase alcalina óssea são mais estáveis e reprodutíveis. Adicionalmente, os níveis de marcadores bioquímicos, principalmente os de formação, variam ao longo do ciclo menstrual, sendo mais elevados durante a fase lútea, comparativamente à fase folicular (10). Alterações importantes de função renal também podem interferir significativamente no metabolismo e excreção dos marcadores bioquímicos, principalmente da osteocalcina. Em função de todos os aspectos discutidos, a interpretação correta de valores de marcadores bioquímicos do metabolismo ósseo requer conhecimento das condições de coleta da amostra, bem como da condição geral do paciente.

\section{MARCADORES DE FORMAÇÃO ÓSSEA}

\section{Fosfatase Alcalina Óssea}

Esta enzima é codificada pelo gene, tecido não-específico, AlP, localizado no cromossoma 1. A isoenzima óssea é um peptídeo de 507 amino ácidos, cuja seqüên- 
cia é exatamente igual à da isoenzima hepática; a diferença entre elas se dá na glicosilação, um fenômeno pós-tradução. Em condições normais, as duas formas predominantes em circulação ( $>90 \%$ do total) de fosfatase alcalina, são a óssea e a hepática, em quantidades equivalentes. A outra forma circulante, em concentrações significativas, é a forma intestinal, que representa menos de $5 \%$ do total. A fosfatase alcalina é uma ectoenzima, ou seja, está localizada na superfície externa da célula onde exerce sua atividade. Quando ancorada na superfície celular, a enzima está na forma de um tetrâmero, sendo que quando liberada para a circulação, por ação das fosfolipases C e D, o é na forma dimérica. No caso da isoenzima óssea, a atividade e a importância da enzima na formação e mineralização da matriz óssea ainda é mal definida. As alterações encontradas na hipofosfatasia, doença devida a uma mutação no gene codificador da enzima, predominantemente osteomalácia, sugerem fortemente que a enzima tenha papel fundamental na mineralização.

Durante muitas décadas, a medida da atividade total de fosfatase alcalina foi a base do estudo de patologias tanto ósseas como hepáticas, partindo-se do pressuposto de que o aumento da atividade total seria devida à isoenzima específica da patologia. Em linhas gerais, este raciocínio é válido principalmente naquelas patologias onde existe um incremento significativo, como a doença de Paget ou doenças obstrutivas hepáticas. No entanto, nas condições em que se espera uma alteração muitas vezes sutil dos níveis sericos, torna-se óbvia a perda de sensibilidade e especificidade da dosagem da atividade total da fosfatase alcalina. Inúmeros métodos foram descritos com o intuito de separar a atividade das duas isoenzimas, sendo os mais empregados a inativação térmica c a precipitação específica com lectinas (11). Com a descrição recente de anticorpos monoclonais específicos para a enzima óssea (12), alguns métodos específicos foram descritos, dos quais dois merecem maior atenção, um baseado na captura específica da enzima e posterior revelação por sua atividade enzimática intrínseca (13), e outro um ensaio imunométrico de dupla identificação (14). A reatividade cruzada com fosfatase alcalina hepática é, nos dois métodos, em torno de $15 \%$ e não existem estudos que mostrem superioridade de um método sobre outro. Um aspecto relativo ao uso e interpretação dos valores de fosfatase alcalina óssea é o fato de que eles não aumentam exclusivamente com o aumento da formação óssea, mas também na osteomalácia. Esta observação torna a enzima um ótimo marcador para o acompanhamento do tratamento da osteomalácia com vitamina $\mathrm{D}$.

\section{Osteocalcina}

A osteocalcina é um peptídeo secretado pelos osteoblastos maduros, condrócitos hipertrofiados e odontoblastos. Apesar de ser primariamente depositada na matriz óssea recém formada, uma pequena fração entra em circulação, caracterizando esta proteína como marcador da atividade osteoblástica. Apesar de ser depositada em quantidades significativas na matriz óssea, sendo uma das proteínas năo-colágenas mais abundantes, não é um marcador de reabsorção óssea pois é totalmente destruída quando da reabsorção promovida pelos osteoclastos. A osteocalcina é constituída por 49 amino ácidos, sendo três (posições 17,21 e 24) constituídos por ácido gama-carboxiglutâmico (Gla), o que lhe dá a peculiaridade de ligar cálcio. A função ou funções da osteocalcina são ainda mal definidas, apesar de sua estrutura indicar interação com cálcio e com cristais de hidroxiapatita. Adicionalmente, estudos indicam que o aparecimento e aumento de produção da proteína são coincidentes com o início do processo de mineralização (15). A produção de osteocalcina é um marcador do osteoblasto maduro (15). Outros estudos, in vitro e in vipo, sugerem que a osteocalcina tenha importante papel no recrutamento e diferenciação dos osteoclastos (16).

A osteocalcina circula em diferentes formas moleculares, que incluem a forma intacta $1-49(36 \%)$, um fragmento amino-terminal grande $1-43(40 \%)$ e fragmentos menores (ar 1-19, 20-43, 29-49, 34\%) (17). A excreção destes diferentes peptídeos depende da integridade da função renal, de maneira que mesmo pequenas disfunções renais podem levar a aumentos diferenciados das diferentes formas circulantes. $\mathrm{O}$ fato de várias formas de osteocalcina serem encontradas normalmente no soro e da metabolização de algumas ser dependente da integridade da função renal, torna mais complexa a interpretação dos resultados obtidos pelos diferentes métodos de medida de osteocalcina sérica. Esta é uma razão pela qual os estudos comparativos entre métodos radioimunológicos mostraram diferenças significativas entre eles, diferenças estas independentes do padrão de referência empregado (18). O desenvolvimento de ensaios imunométricos baseados em anticorpos monoclonais tornou os resultados cias dosagens com diferentes métodos mais comparáveis $(19,20)$. No entanto, a interpretação dos níveis de osteocalcina deve levar em consideração uma série de fatores: desde a metodologia empregada até as condições de coleta, pois o peptídeo é susceptível a proteólise e deve ser coletado e manipulado com cuidados especiais para evitar a degradação. Adicionalmente, os níveis de osteocalcina também observam 
ritmo circadiano, com valores decrescentes durante a manhã, elevando-se lentamente à tarde e atingindo o pico em torno de meia noite (2l). Uma observação adicional, e que comprova o fato de que a osteocalcina mede atividade osteoblástica em estágio diferente da medida pela fosfatase alcalina óssea, é o fato da correlação entre as duas medidas ser bastante baixa (22).

\section{MARCADORES DE REABSORÇÃO ÓSSEA}

\section{Hidroxiprolina}

A excreção urinária de hidroxiprolina é um marcador clássico da reabsorção óssea, tendo sido usado durante décadas em pesquisa e diagnóstico. No entanto, o fato da hidroxiprolina não ser limitada ao osso, nem mesmo ao colágeno, contribuiu muito para o seu gradual abandono como exame de referência. De fato, o componente $\mathrm{Clq}$ do complemento é rico em hidroxiprolina e pode contribuir com até $40 \%$ do total excretado; além disto, a excreção é dependente da dieta, desde que alguns alimentos comuns (que contenham gelatina) podem contribuir significativamente para o pool de amino ácido excretado (17). Desta maneira, com o desenvolvimento dos métodos mais específicos para avaliação da reabsorção óssea, a medida de hidroxiprolina tem sido abandonada.

\section{Interligadores do Colágeno}

Durante a maturação do colágeno, as fibrilas colágenas recém depositadas na matriz extracelular são estabilizadas pela interligação entre radicais lisina e hidroxilisina de diferentes cadeias. Assim, por ação da enzima lisil oxidase, moléculas de lisina e hidroxilisina da porção terminal (telopeptídeos) das moléculas de colágeno formam aldeídos e se condensam com o resíduo de molécula adjacente formando uma estrutura interligadora composta de três radicais hidroxilisina (piridinolina) ou uma lisina e duas hidroxilisinas (deoxipiridinolina). As piridinolinas atuam como interligadores (cross-links) nos colágenos tipo I, II e III, os principais de todos os tecidos com exceção da pele (23). As proporções piridinolina:deoxipiridinolina variam de acordo com o tipo de colágeno, sendo menores no colágeno tipo I. Estas interligações ocorrem essencialmente em duas regiões da fibrila colágena: na região amino-terminal, onde dois amino-telopeptídeos se ligam na altura do resíduo 930 e na região carboxi-terminal, onde dois carboxi-telopeptídeos se ligam na altura do resíduo 87. O arranjo espacial desta estrutura pode ser visualizado na figura 1 .

Quando os osteoclastos reabsorvem o tecido ósseo, eles o fazem através da secreção de uma mistura de proteases ácidas e neutras, que agindo seqüencialmente degradam as fibrilas colágenas em fragmentos de diferentes tamanhos. Os produtos e degradação que são jogados em circulação variam desde amino ácidos livres até fragmentos carboxi e amino-terminais contendo interligadores (C e N-telopeptídeos). Os fragmentos liberados pelos osteoclastos são adicionalmente metabolizados pelo figado e rins, de maneira a resultar em fragmentos suficientemente pequenos para serem excretados pelos rins por simples filtração glomerular. As piridinolinas, livres ou ligadas a fragmentos amino ou carboxi-terminais, têm uma série de vantagens sobre a hidroxiprolina como marcadores de reabsorção óssea. Eles só se originam de fibrilas colágenas extracelulares e maduras, os peptídeos amino ou carboxi-terminais têm seqüências características do colágeno de onde se originaram (ex.: colágeno tipo I), e apesar de estarem presentes na dieta, aparentemente não são absorvidos. As metodologias existentes para a medida dos interligadores do colágeno evoluíram bas-

Figural. Estrutura e localizaçăo dos interligados do colágeno tipo l.

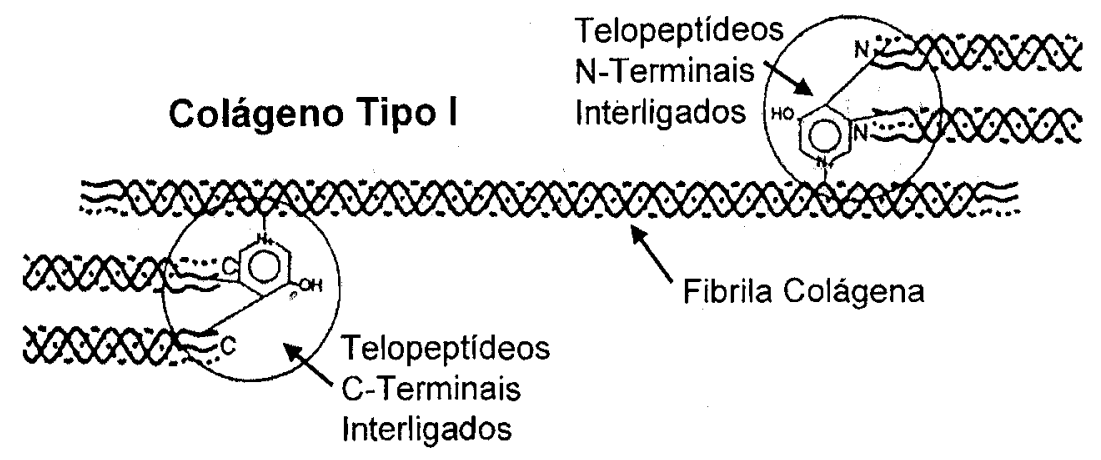


tante nos últimos anos. Os primeiros métodos descritos que tiveram aplicação prática foram os baseados em técnicas de Cromatografia Líquida de Alta Performance (HPLC) e medem simultaneamente a piridinolina e a deoxipiridinolina totais $(24,25)$. Estes métodos implicam em hidrólise prévia das amostras e se baseiam na detecção das piridinolinas com base em sua fluorescência natural. Foram aplicados extensivamente, inclusive em nosso meio (26), e apresentam boa reprodutibilidade. No entanto, são métodos muito laboriosos, demorados e bastante dispendiosos, daí a procura por metodologias alternativas, mais rápidas, práticas e baratas. Dentre as alternativas disponíveis destacaram-se os métodos imunológicos baseados em anticorpos específicos contra as estruturas dos interligadores. Podemos classificá-los em três tipos:

a.os baseados em anticorpos contra as piridinolinas livres (piridinolina e/ou deoxipiridinolina), comercializados por Metra Biosystems, Palo Alto, CA - USA;

b.os baseados $\mathrm{em}$ anticorpo que reconhece a sequiência que inclui os interligadores $\mathrm{N}$-terminais ( $\mathrm{N}$ telopeptídeo), comercializado como NTx por Ostex International Inc., Seattle, WA - USA e J\&J Diagnósticos;

c.os baseados em anticorpos dirigidos contra a seqüência que inclui os interligadores $\mathrm{C}$-terminais (Ctelopeptídeo), comercializado como Crosslaps por Osteometer, Rodrove, Dinamarca.

Uma série de trabalhos têm sido publicados na literatura recente procurando demonstrar algum tipo de vantagem de uma metodologia em relação a outra. A análise conjunta dos trabalhos mostra que, se existe superioridade de algum dos três ensaios em relação aos outros, esta é bastante marginal. Poderíamos considerar que qualquer um dos três é um bom método para estudar a reabsorção óssea, sendo os métodos de escolha no momento.

\section{UTILIDADE DOS MARCADORES BIOQUÍMICOS DO METABOLISMO ÓSSEO NO DIAGNÓSTICO E SEGUIMENTO DE PATOLOGIAS ÓSTEO-METABÓLICAS}

O uso dos marcadores bioquímicos se estende, teoricamente, a qualquer condição que leve a uma alteração do metabolismo do tecido ósseo, com incremento on diminuição da remodelação óssea. Condições de aplicação óbvia dos marcadores são no diagnóstico e seguimento de patologias ósseas onde são encontradas importantes alterações do metabolismo ósseo, como na doença de Paget, no raquitismo, no hiperparatiroidismo primário e outras mais raras. No caso de pacientes com alterações ósseas induzidas pelo uso de corticosteróides, o emprego da dosagem de osteocalcina tem indicação precisa desde que é o marcador mais precocemente alterado. No entanto, começa a se abrir, com os novos métodos mais específicos, a possibilidade do uso dos novos marcadores em situações clínicas de muito maior abrangência, como por exemplo, na osteoporose.

Utopicamente, o marcador bioquímico ideal seria aquele que nos permitiria discriminar qual o paciente que se beneficiaria de tratamento preventivo contra a osteoporose, e permitiria avaliar precocemente o grau de resposta à terapêutica introduzida. Quanto ao primeiro item, trabalhos recentes correlacionam o início da menopausa com aumento significativo dos marcadores bioquímicos, e que este aumento estaria relacionado com a posterior perda de massa óssea $(27,28)$. Seria, pois, possível discriminar as pacientes que evoluiriam com perda óssea aumentada daquelas que apresentariam perda óssea dentro dos limites normais para a idade e condição hormonal. Neste sentido, todos os marcadores bioquímicos mostraram-se úteis, com possivel vantagem para os interligadores de colágeno. Vale salientar que os resultados destes estudos, e de muitos outros $(29,30)$ mostram resultados válidos quando analisados em conjunto, ou seja, populaçăo com perda óssea contra população sem perda óssea. A transferência dessas informações para o caso individual é muitas vezes difícil, se não impossível; em outras palavras, o uso dos marcadores bioquímicos no diagnóstico de osteoporose é, atualmente, injustificado.

Quanto ao segundo item, ou seja, se os marcadores bioquímicos poderiam servir como sinalizadores precoces do sucesso ou insucesso de uma determinada tcrapia, muitas evidências indicam que sim. A necessidade, neste caso, seria de um marcador mais precoce de ação terapêtutica, desde que os efeitos retratados por mudanças na densitometria óssea são discerníveis apenas a longo prazo (mais de um ano). É atualmente consenso que os marcadores bioquímicos preenchem tal necessidade, independentemente do tipo de terapêutica empregada $(8,31,32)$. Os marcadores de reabsorção aparentemente respondem mais rapidamente ( 1 mês) do que os de formação ( 3 meses) ao tratamento com alendronato, mas a informação final é equivalente (8). Tal resposta permite ao médico assistente uma intervenção precoce na conduta terapêutica, de maneira a otimizar os resultados sem necessidade de esperar pelas alterações densitométricas que ocorrerem a longo prazo. Importante salientar que a variação nos níveis do marcador bioquímico aceitos como significativos dependem das variações intra-individuais intrínsecas de cada um. Assim, 
os marcadores urinários de reabsorção óssea do tipo NTx necessitam de variações acima de $30 \%$ para serem consideradas significantes, enquanto que as variações dos marcadores séricos de formação podem ser menores, na faixa de 15 a $20 \%$.

\section{PERSPECTIVAS FUTURAS}

A evolução no campo de estudo dos marcadores bioquímicos do metabolismo ósseo deverá se acelerar nos próximos anos por uma série de razões. A primeira delas tem a ver com o acúmulo de experiência com o emprego dos marcadores que vem ocorrendo nos últimos anos, além da queda do preço dos testes e sua maior disponibilidade. Uma série de trabalhos estão sendo desenvolvidos, especialmente em caracter prospectivo, o que deverá dar maior credibilidade e aceitação em relação aos resultados obtidos. Outro aspecto é o desenvolvimento recente de metodologias para a dosagem de marcadores de reabsorção em soro e não na urina; como exposto acima, o uso de dosagens urinárias traz consigo um erro inerente à excreção e à correção com relação à excreção de creatinina. Finalmente, como tem ocorrido em áreas de intensa pesquisa, devemos esperar o surgimento de novos e melhores marcadores do metabolismo ósseo, que mais se aproximem do teste ideal. Isto aceitando que dispomos atualmente de marcadores que muito se aproximam deste ideal, em especial os telopeptídeos, apenas que por ignorar princípios básicos do metabolismo ósseo, muitas vezes queremos obter deles informações que eles nunca poderão nos dar.

\section{REFERÊNCIAS}

1. Rauch F, Schonau E. Woitge $H$, et al. Urinary excretion of hydroxy-piridinium cross-links of collagen reflects skeletal growth velocity in normal children. Exp Clin Endocrinol 1994; 102:94-7.

2. Sowers M. Eyre D, Hollis BW, ef al. Biochemical markers of bone turnover in lactating and nonlactating postpartum women. J Clin Endocrinol Metab 1995:80:2210-6.

3. Kushida K, Takahashi M, Kawana K. Inove $T$. Comparison of markers for bone formation and resorption in premenopausal and postmenopausal subjects and osteoporotic patients. J Clin Endocrinol Metab 1995;80:2447-50

4. Wishart JM, Need AG, Horowitz $M$, et al. Effect of age on bone density and bone turnover in men. Clin Endocrinol (Oxf) $1995: 42: 141-6$.

5. Stein GS, Lian JB. Molecular mechanisms mediating proliferation/differentiation interrelationships during progressive development of the osteoblast phenotype. Endocrin Rev 1993;14:424-42.

6. Alvarez L, Guanabens N. Pens P, ef al. Discriminative value of biochemical markers of bone turnover in assessing the activity of Paget's disease. J Bone Miner Res

\section{$1995 ; 10: 458-65$.}

7. Demiaux B. Arlot ME, Chapuy MC, et al. Serum osteocalcin is increased in patients with osteomalacia: correlations with biochemical and histomorphometric findings. J Clin Endocrinol Metab 1992;74:1146-51.

8. Garnero P. Shih WJ, Gineyts E, et al. Comparison of new biochemical markers of bone turnover in late postmenopausal osteoporotic women in response to alendronate treatment, J Clin Endocrinol Metab 1994:79: 1693-700.

9. Sarainen $S$, Tahtela $R$, Laitinen $K$, et al. Nocturnal rise in markers of bone resorption is not abolished by bedtime calcium or calcitonin. Clacif Tissue Int 1994;55:349-52.

10. Nielsen HK, Brixen K, Bouillon R, Mosekilde L. Changes in biochemical markers of osteoblastic activity during the menstrual cycle. J Clin Endocrinol Metab 1990:70:1431-7.

11. Farley JR, Hall SL, Herring S, et al. Reference standards for quantification of skeletal alkatine phosphatase activity in serum by heat inactivation and lectin precipitation. Clin Chem 1993:39:1878-84.

12. Hill CS, Wolfert RL. The preparation of monoclonal antibodies which react preferentially with human bone alkaline phosphatase and not liver alkaline phosphatase. Clin Chim Acta 1989: 186:315-20.

13. Gomez Jr B. Ardakani S, Ju J, et al. Monoclonal antibody assay for measuring bone-specific alkaline phosphatase activity in serum. Clin Chem 1995:41:1560-6.

14. Garnero P. Delmas PD. Assessment of the serum levels of bone alkaline phosphatase with a new immunoradiometric assay in patients with metabolic bone disease. $J$ Clin Endocrinol Metab 1993; 77: 1046-53.

15. Owen TA, Aronow M. Shalhoub $V$, et al. Progressive development of the rat osteoblast phenotype in vitro: reciprocal relationships in expression of genes associated with osteoblast proliferation and differentiation during formation of the bone extracellular matrix. J Cell Physiol 1990; 143:420-30.

16. Chenu C, Colucci S, Grano M, et al. Osteocalcin induces chemotaxis, secretion of matrix proteins and calcium-mediated intracellular signaling in human osteoclast-like cells. J Cel Biol 1994; 127; 1149-58.

17. Delmas PD. Biochemical markers of bone furnover I: theoretical considerations and clinical use in osteoporosis. Amer J Med 1993;95:115-16S.

18. Delmas PD, Christiansen C, Mann KG. Price PA. Bone gla protein (ostocalcin) assay standardization report. J Bone Min Res 1990;5:5-10.

19. Garnero P. Grimaux M, Demiaux B, et al. Measurement of serum osteocalcin with a human specific two-site immunoradiometric assay. J Bone Miner Res 1992;7:1389-98.

20. Hosoda K, Eguchi H, Nakamoto T, et al. Sandwich immunoassay for intact human osteocalcin. Clin Chem 1992;38:2233-8.

21. Nielsen HK. Circadian and circatrigintan changes in osteoblastic activity assessed by serum osteocalcin. Dan Med Bull 1994:41:216-27

22. Diaz Diego EM, Diaz Martin MA, de la Piedra C, Rapado A. Lack of correlation between levels of osteocalcin 
and bone alkaline phosphatase in healthy control and postmenopausal osteoporotic women. Horm Metabol Res 1995;27:151-4.

23. Eyre D. Collagen cross-linking amino acids. Methods Enzymol 1987; 144:115-36.

24. Eyre DR, Koob TJ, Van Nees KP. Quantitation of hydroxypiridinium crosslinks in collagen by high-performance liquid chromatography. Anal Biochem 1984;137:380-8.

25. Uebelhart D, Gineyts E, Chapuy MC, Delmas PD. Urinary excretion of pyridinium crosslinks: a new marker of bone resorption in metabolic bone disease. Bone Miner 1990;8:87-96.

26. Amarante ECJ, Kasamatsu TS, Kunii IS, Vieira JGH. Avaliação da excreção urinária de piridinolina e deoxipiridinolina em pacientes com hipertiroidismo e sua correlação com niveis de hormônios tiroideanos e densidade mineral óssea. Arq Bras Endocrinol Metab 1996:40:258-63

27. Garnero P, Sornay-Rendu E, Chapuy M, Delmas PD Increased bone turnover in late menopausal women is a major determinant of osteoporosis. J Bone Miner Res 1996: 11:337-49.

28. Schlemmer A, Hassager C. Delmas PD, Christiansen C. Urinary excretion of pyridinium cross-links in healthy women; the long term effects of menopause and estrogen/progesterone therapy. Clin Endocrinol (OXf) 1994:40:777-82.

29. Eastell R, Robins SP, Colwell T, et al. Evaluation of bone turnover in type I osteoporosis using biochemical markers specific for both bone formation and bone resorption. Osteoporos Int 1993:3:255-60.

30. Seibel MJ, Cosman F, Shen V, ef al. Urinary hydroxypyridinium crosslinks of collagen as markers of bone resorption and estrogen efficacy in postmenopausal osteoporosis. J Bone Miner Res 1993;8:881-9.

31. Adami S, Passeri M, Ortolani S, et al. Effects of oral alendronate and intranasal calcitonin on bone mass and biochemical markers of bone turnover in postmenopausal osteoporosis. Bone 1995;17:383-90.

32. Bikle DD. Biochemical markers in the assessment of bone disease. Am J Med 1997; 103:427-36.

\section{Endereço para correspondência:}

José Gilberto H. Vieira

Laboratório Fleury

Rua Cincinato Braga 282

01333-910 São Paulo, SP

e-mail: jose.vieira@fleury.com.br 